\title{
Hirschsprung's disease and medullary thyroid carcinoma
}

Viroj Wiwanitkit

Accepted: 26 March 2012/Published online: 18 April 2012

(C) Springer-Verlag 2012

Sir, the recent publication on Hirschsprung's disease (HD) and medullary thyroid carcinoma (MTC) is very interesting [1]. Vaclavikova et al. [1] concluded for "the benefit of systematic RET mutation screening in HD patients in order to identify the risk of MTC in the preclinical stage of the disease." There are some considerations. First, the design of this work is only descriptive study (retrospective and prospective); hence, the risk cannot be concluded. The use of analytical study with control group is required. Second, only RET mutation was tested. There might be the effects from other possible mutations that were not completely studied in this work. Finally, the previous report [2] stated only exon 10 and 13 significance, but the present report stated for exon 10, 11 and 13 [1]. Of interest, the difference in detected RET mutations in different publications from different settings [1,2] might imply the possible effect of race and ethnicity. This can be the further topic for studies.

\section{References}

1. Vaclavikova E, Kavalcova L, Skaba R, Dvorakova S, Macokova P, Rouskova B, Bendlova B (2012) Hirschsprung's disease and medullary thyroid carcinoma: 15-year experience with molecular genetic screening of the RET proto-oncogene. Pediatr Surg Int 28(2): $123-128$

2. Skába R, Dvoráková S, Václavíková E, Vlcek P, Frantlová M, Bendlová B (2006) The risk of medullary thyroid carcinoma in patients with Hirschsprung's disease. Pediatr Surg Int 22(12):991995
V. Wiwanitkit $(\bowtie)$

Wiwanitkit House, Bangkhae, Bangkok, Thailand

e-mail:wviroj@yahoo.com 